\title{
XVIII.
}

Aus der Königl. Universitäts-Ohrenklinik zu Berlin. Director Geh. Med.-Rath Prof. Dr. Lueae.

\section{Graviditätsvaricen im Meatus externus, an der Concha und in deren Umgebung rechterseits.}

\author{
Von
}

\author{
Dr. Warnecke, Assistenzarzt,
}

Ein Fall von obengenannter durch ihre Localisation merkwürdiger, und soweit ich die einsehlägige Litteratur ubberblicke, bisher noch nicht beschriebener Gefässanomalie kam uns am 1. April $1897 \mathrm{zur}$ Beobachtung.

Frau Borch, 36 Jahre alt, bekam, angeblich vor 15 Jahren (1883) in ihrer ersten Schwangerschaft Anschwellungen von blaurother Farbe im Gehörgang, an, über und binter der Concha ohne sonstige Erscheinungen. Dieselben bildeten sich nach der Schwangerschaft nicht völlig, sondern nur zur Hälfte wieder zurück. In der zweiten, noch mehr in der dritten Schwangerschaft entwickeiten sich die Anschwellungen stärker. In der dritten Schwangerschaft erfolgte ebenso wie in der vierten verschiedentlich Blutung aus einzelnen der Knoten, einige Male ziemlich heftig. Seitdem sind Blutungen nicht wieder aufgetreten, auch ist eine weitere Vergrösserung, gegenüber der in der dritten Schwangerschaft erreichten, nicht erfolgt. Nach der Geburt tritt stets Rückbildung etwa bis zur Hälfte der während der Schwangerschaft erreichten Grösse in 2-3 Wochen ein. Die Vergrösserung während der Schwangerschaft tritt bereits gegen Ende des ersten Drittels derselben ein, ist mit continuirlichem, bei stărkerer körperlicher Anstrengung gesteigertem Sausen und Klopten, sowie mit zeitweise ziemlich heftigem Jucken verbunden. Diese Erscheinungen pflegen mit Rückgang der stärkeren Schwellung nach der Geburt auch $\mathrm{zu}$ verschwinden.

Seit 16 Jahren leidet Patientin an Klopfen auch oben im Kopf und Kopfschmerzen. Sie ist zum zehnten Male gravida, ist angeblich stets gesund gewesen. Vor der Verheirathang war die rechte Ohrmuschel völlig normal und unterschied sich in nichts von der linken. Die unten zu erwähnenden Flecke auf der Wange sollen jedoch schon damals bestanden baben, nur nicht roth, wie jetzt, sondern weiss, wie die übrige Haut, und mit rothem Rande umgeben gewesen sein.

Der Befund war folgender: Blaurother Tumor vor, über und hinter der Concha, nach vorn sich bis über den Tragus hinaus nach unten erstreekend, hier ea. $1 \mathrm{~cm}$ breit, nach oben bis zur Haargrenze und etwas uber dieselbe hinaus, hier ea. $2,5-3,0 \mathrm{~cm}$ breit, nach unten bis zur Mitte der Hinterfläche der Concha, hier $2,5 \mathrm{~cm}$ breit, herunterreichend. Helix am oberen Rande 
ca. $0,75 \mathrm{~cm}$ breit, rothblau, mit zahlreichen varicösen Verdickungen. In der oberen Hälfte der Scapha desgleichen varieöse Anschwellungen, jedoch weniger zahlreich. Tragus nur wenig verändert, dagegen prominiren ins Lumen des Gehörganges hinein zwei röthliche Tumoren von gleichem Charakter, der eine von der oberen, der andere von der vorderen Wand entspringend. Der von der oberen Wand entspringende ist etwa kleinerbsen-, der andere linsengross. Beide lassen sich mit mittelgrossem $\mathrm{Ohr}$ trichter zur Seite drängen und ermöglichen den Blick anf das vollkommen normale Trommelfell und den ebenfalls im übrigen völlig normalen Gehörgang.

An dem oberhalb der Concha gelegenen, auf seiner höchsten Höhe ca. $1,5 \mathrm{~cm}$ über das Niveau der umgebenden Haut prominirenden Tumor fühlt der ohne Druck aufgelegte Finger Schwirren.

$\mathrm{Am}$ anderen $\mathrm{Ohr}$ keine Abnormitäten. Zahlreiche Varicen an Ober- und Unterschenkeln, sowie sehr stark an beiden Füssen, hier besonders an den Aussenseiten. Am rechten Fuss hat in letzter Zeit Blutung aus einem in Mitte des Seitenrandes gelegenen geplatzten Varix stattgefunden. Sonstige Beschwerden der im 8. Monat graviden Frau gering. Am Thorax keine Varicositäten. An der rechten Wange zwei $1 \mathrm{~cm}$ im Durohmesser haltende, nahezu runde, duroh Vasodilatation gebildete Flecke ohne Prominenz uber die umgebende Haut.

Im Herbst 1897 stellte sich die Frau nach erfolgter Geburt wieder vor. Ausdehnung und Aussehen der Varicositäten im grossen und ganzen dasselbe, nur Prominenz über das Niveau der Umgebung etwa um die Hälfte verringért.

Am 8. Juli 1898 kam Patientin wieder, sie ist wieder gravida, und zwar im 3. Monat. Die Varicositäten sind schon wieder bedeutend stärker wie bei der Untersuchung im Herbst, wenn auch noch nicht so stark wie bei der ersten Untersuchung.

Am 3. August 1898 erneute Vorstellung. Patientin hat am 22. Juli abortirt, die Ausräumung des Abortes erfolgte in der Königlichen UniversitätsFrauenklinik hierselbst. Trotzdern der Abort erst 14 Tage zurückliegt, sind die váricösen Anschwellungen schon wieder bedeutend zurückgegangen, sie entsprechen fast schon wieder dem Aussehen, welches sie im Herbst vorigen Jahres boten, sie sind blass, längst nicht mehr so prominent, man fühlt auf der Höhe der oberhalb der Concha gelegenen grössten Prominenz kein Schwirren mehr. Die kugeligen, ins Innere des Meatus hineinragenden Tumoren sind fast ganz verschwunden.

Irgend welche therapeutischen Eingriffe konnten nicht in Frage kommen, ganz abgesehen davon, dass dieselben nicht gewünscht wurden. Die Fran kam nur zu uns, nm sich zu vergewissern, ,dass aus der Sache nichts Schlimmes entstehen könnte."

Eine Erklärung dieser merkwürdigen Anomalie vermag ich bei dem vollkommen normalen Befunde an den Hals- und Brustorganen nicht zu geben. 